\title{
Association between Glutathione-S-Transferase and Gastric Carcinoma: A Case Control Study
}

\author{
Ranjit S. Ambad ${ }^{1}$, Priya Koundal ${ }^{2}$, Akansha Singh ${ }^{3}$, Roshan Kumar Jha ${ }^{4}$
}

${ }^{1}$ Department of Biochemistry, Datta Meghe Medical College, Nagpur, Maharashtra, India. ${ }^{2}$ Department of Biochemistry, Dr. Ulhas Patil Medical College and Hospital, Jalgaon, Maharashtra,

India. ${ }^{3}$ Department of Biochemistry, Dr. Ulhas Patil Medical College and Hospital, Jalgaon, Maharashtra, India. ${ }^{4}$ Department of Biochemistry, Jawaharlal Nehru Medical College, AVBRH

(Datta Meghe Institute of Medical Sciences) Sawangi, Wardha, Maharashtra, India.

\section{ABSTRACT}

\section{BACKGROUND}

Gastric carcinoma is the fourth most common cancer type and the second leading cause of cancer deaths worldwide. Every year, around 1 million new cases and 0.7 million deaths are caused due to gastric carcinoma. Gastrointestinal tract is involved in absorption and metabolism of toxic or potentially carcinogenic compounds which may be present in the food we eat. In this context, digestive tract may be considered as a major site of cancer in humans. Glutathione-S-Transferase (GST) is an important metabolizing enzyme, present in the epithelial cells of human GIT. As nearly all reactive, ultimate carcinogenic forms of chemicals are electrophiles, GST is substantially important as a mechanism for carcinogen detoxification. The present study was conducted to evaluate the role of GST in gastric carcinoma and analyse the level of serum GST in patients suffering from gastric carcinoma.

\section{METHODS}

This is a case control study, conducted among 50 cases of gastric carcinoma and 50 age sex matched controls. Patients included in this study were diagnosed with gastric carcinoma, after clinical and histological examination. Circulating levels of GST were assayed in the in the serum of control group and in patients with gastric carcinoma, using standardized method.

\section{RESULTS}

Mean GST activity in serum was significantly higher $(\mathrm{p}<0001)$ in gastric carcinoma patients $(8.24 \pm 1.94)$ as compared to control $(5.47 \pm 0.52)$. After chemotherapy $(12.34 \pm 1.05)$ the activity of GST was significantly higher $(\mathrm{p}<0001)$ than before chemotherapy $(10.23 \pm 2.12)$. The generation of free radicals is as reflected by increased GST and GST- $\pi$ activity in carcinoma cases.

\section{CONCLUSIONS}

Serum GSTs measurement in plasma may be a useful tumour marker in stomach cancer and serum GSTs activity might be helpful in predicting the response of chemotherapy in advanced stages of cancer. GST values are helpful in predicting the radiation response. Overexpression of GST in neoplasia may be causal, allowing replicative advantage, or casual, accompanying clonal expansion. The major limitation to its widespread use is the time needed for doing the assay and until this is overcome it will remain primarily a research tool.

\section{KEY WORDS}

Cisplatin, Gastric Cancer, Tumour Marker, Chemotherapy, Glutathione-S-Transferase, ROS, GIT

\author{
Corresponding Author: \\ Dr. Roshan Kumar Jha, \\ Department of Biochemistry, \\ Jawaharlal Nehru Medical College, \\ AVBRH, Datta Meghe Institute of \\ Medical Sciences, Sawangi, \\ Wardha, Maharashtra. \\ E-mail: rossssan47@gmail.com
}

DOI: $10.14260 /$ jemds/2020/606

How to Cite This Article:

Ambad RS, Koundal P, Singh A, et al. Association between glutathione - $S$ transferase and gastric carcinoma: a case control study. J Evolution Med Dent Sci 2020;9(38):2783-2786, DOI: 10.14260/jemds/2020/606

Submission 09-05-2020,

Peer Review 14-08-2020,

Acceptance 20-08-2020,

Published 21-09-2020.

Copyright (C) 2020 Ranjit S. Ambad et al. This is an open access article distributed under Creative Commons Attribution License [Attribution 4.0 International (CC $B Y 4.0)]$ 


\section{BACKGROUND}

Gastric carcinoma is currently the fourth most common cancer type and second leading cause of cancer deaths worldwide. ${ }^{1}$ Every year, around 1 million new cases and 0.7 million deaths are caused due to gastric carcinoma. ${ }^{2}$ Principal factors responsible for gastric carcinoma, are nutritional, genetic factors and infectious factors. Indeed, cigarette smoking has been a risk factor in development of gastric cancer. Carcinogens such as benzo $[\alpha]$ pyrene present in tobacco play vital role in gastric carcinoma. ${ }^{3}$ Natural elements including dietary propensities are significant in its turn of events, utilization of salted, smoked, cured and safeguarded food wealthy in salt, nitrite and N-nitro mixes have been accounted for to be related with an expanded danger of gastric cancer. ${ }^{4}$ Smoking and liquor utilization have been proposed as hazard factors for gastric disease in some epidemiological investigations however their job has been inconsistent.5,6 Also dietary factors have been concentrated in some epidemiological investigations from India, however their job has not been reliably proven ${ }^{6}$ certain substances in the eating routine may increase. GI carcinoma hazards for e.g. there have been proposals so far not all around demonstrated that an eating regimen high in prepared meat may expand the danger of GI carcinoma drinking extremely hot fluids often. In late year GSTs have pulled in enthusiasm for the field of malignant growth in light of the fact that their movement is promptly expanded in synthetically incited tumours. ${ }^{7}$ There catalysts catalyse the conjugation of GSH to an assortment of electrophilic mixes, receptive compound for sure GSTs are one of the proteins by subterranean insect cancer-causing agents and in this manner can forestall tumour development GSTs have likewise been recommended to assume a significant job in various medication opposition in malignant growth chemotherapy ${ }^{8}$ may expand the hazard for oesophageal carcinoma. This may be the aftereffect of long haul harm the fluids do to the cell covering the throat. Indulging which prompts stoutness, increments the danger of GI carcinoma. Then again, eating less carbs high in leafy foods have various nutrients and minerals that may help forestall carcinoma. ${ }^{9}$

Gastrointestinal carcinoma aids to threatening states of the gastrointestinal tract (GIT) and adornment organ of assimilation and it incorporates throat, stomach, biliary framework, pancreas, small digestive system, internal organ, rectum and butt. The side effect identifies with the organ influenced and can incorporate block, strange draining or other related issues. The conclusion regularly requires blood test, pee test, stool test endoscopy and biopsy of dubious tissue. The tumour, just as the kind of threatening cell and whether it has attacked their tissues or spread somewhere else. These components likewise decide the visualization of sickness. Generally, the GI tract and the frill organs i.e., pancreas, liver and nerve bladder are answerable for additional malignancies and a larger number of passages from GI carcinoma than some other framework in the body. There is huge geographic variety in the paces of various gastrointestinal carcinomas. ${ }^{10}$

GI carcinoma is just one of the most widely recognized carcinoma yet in addition one of the most well-known reasons for carcinoma mortality. A brief glance at GLOBOCAN information 2012 demonstrated that out of evaluated 1.01 million new cases in the year 2012. In India, 227,000 were situated in GI tract. Out of around 682,000 carcinoma related deaths, 182,000 deaths were a direct result of GI carcinoma. ${ }^{11}$ The six most basic GI carcinomas are associated carcinoma gastric, throat, liver, gallbladder and pancreas. ${ }^{12}$ Gastric Carcinoma does not show any symptoms for long period of time. Symptoms include weight reduction, stomach torment, queasiness, heaving, changed bowel habits. Metastases to supraclavicular lymph nodes may be the first clinical sign.

\section{Grouping of Gastric Carcinoma}

The world wellbeing association and the Japanese grouping depict extravagantly a few histopathological kinds of gastric carcinoma and are helpful for the visualization dependent on the evaluation of the histological separation of early sore.13 Adenocarcinoma adenosquamous carcinoma, squamous cell carcinoma, little cell carcinoma, undifferentiated carcinoma, other carcinoma. ${ }^{14}$

Gastrointestinal tract is involved in absorption and metabolism of toxic or potentially carcinogenic compounds which may be present in food we eat. In that context digestive tract may be considered as a major site for cancer in humans. GST is important metabolizing enzyme, present in epithelial cells of human GIT.15

Glutathione-S-Transferase is a dimer, divided into $\alpha, \mu, \pi, \theta$ are involved in detoxification of foreign toxic compounds. In an antioxidant defense system GST participates through several mechanisms including ROS and conjugation reactions which further results in synthesis of mercapturic acid and compels carcinogens toxins, and drugs to be excreted. It is also involved in binding of electrophiles to sulphydryl groups of GSH yielding less harmful and more water-soluble molecules which can be excreted via bile or via urine. As nearly all reactive, ultimate carcinogenic forms of chemicals are electrophiles, GSTs takes substantial importance as a mechanism for carcinogen detoxification. ${ }^{16}$

A various number of studies done on the effect of placental, serum and serum glutathione-s-transferase-pi from different regions have suggested that serum GST levels may be elevated in a wide range of gastrointestinal malignancies and thus the measurement of GST level might provide a useful tumour marker. ${ }^{17-20}$

\section{Objectives}

1. To evaluate GST in patients with gastric carcinoma.

2. To compare the role of serum GST activity in cases and controls.

3. To find out correlation of GST with severity of disease.

\section{METHODS}

This is a case control study conducted in a tertiary care hospital over a period of two years among 50 cases diagnosed with gastric carcinoma 20 - 50 years of age (Group 1 - Cases) and 50 age and sex matched controls (Group 2). Healthy control without diabetes, CAD, smoking habits were included in the present study as controls. Patients with other carcinoma were excluded. Around 20 patients were excluded as they were lost during follow-up. All patients underwent 
chemotherapy treatment and drugs such as cisplatin and 5Fluorouracil were administrated.

\section{Collection and Processing of Blood Sample}

$5 \mathrm{ml}$ blood samples were collected, samples were centrifuged for around 10 minutes at $4^{\circ} \mathrm{c}$ at $1000 \mathrm{xg}$. Yellow plasma layer was used for estimation of GST. Plasma was stored at $-80^{\circ} \mathrm{c}$ as per requirement. The blood samples were processed by following standard protocol in the clinical biochemistry laboratory. Plasma GSTs activity was measured by using 1chloro-2, 4 dinitrobenzene (Sigma-Aldrich) as substrate, was measured according to the procedure described by Habig et al. ${ }^{21}$

\section{Statistical Analysis}

All the collected data were submitted to excel worksheet in order to calculate mean and SD for linear variables, $\mathrm{p}$ value were calculated using SPSS version 10 with $95 \%$ confidence interval.

\section{RESULTS}

\begin{tabular}{|ccc|}
\hline & $\begin{array}{c}\text { Number of Subject } \\
\text { (M / F) }\end{array}$ & $\begin{array}{c}\text { Age } \\
\text { (in Years) }\end{array}$ \\
\hline Normal Control & $50(33 / 17)$ & $40-55$ \\
Gastric Carcinoma Patients & $50(33 / 17)$ & $25-75$ \\
Cases Stage 2 before Chemotherapy & $25(16 / 9)$ & $25-69$ \\
Cases Stage 3 after Chemotherapy & $25(17 / 8)$ & $25-75$ \\
\hline \multicolumn{2}{|c|}{ Table 1. General Characteristics of Cases and Controls } \\
\hline
\end{tabular}

Table 1 Depicts: Number of males were more in number as compared to females, all of the cases and controls were in between age group of $25-75$.

\begin{tabular}{|cccc|}
\hline & No. of Subjects (n) & Mean \pm SD & P Value \\
\hline GST Control & 50 & $5.47 \pm 0.52$ & $\mathrm{p}<0.0001$ \\
GST Cases & 50 & $8.24 \pm 1.94$ & \\
\hline Table 2. Comparison of GST Activity in Cases and Controls \\
\hline
\end{tabular}

Table 2 Depicts: Level of GST in control is $5.47 \pm 0.52$ and $8.24 \pm 1.94$ in cases. There is significant $(p<0.0001)$ increase in levels of GST in cases as compared to control.

\begin{tabular}{|c|c|c|c|}
\hline & No. of Subjects (n) & Mean \pm SD & P Value \\
\hline GST Control & 50 & $5.47 \pm 0.52$ & $\mathrm{p}<0.0001$ \\
\hline GST Cases before Chemotherapy & 25 & $10.23 \pm 2.12$ & \\
\hline $\begin{array}{r}\text { Table 3. Comparison } \\
\text { and GST Co }\end{array}$ & $\begin{array}{l}\text { of GST Activity betw } \\
\text { ses before Chemoth }\end{array}$ & $\begin{array}{l}\text { een GST Con } \\
\text { erapy }\end{array}$ & trol \\
\hline
\end{tabular}

Table 3 Depicts: Enzyme activity of GST is increased in cases (10.23 \pm 2.12$)$ as compared to control (5.47 \pm 0.52$)$, and there is a significant $(\mathrm{p}<0.0001)$ difference between cases and controls.

\begin{tabular}{|c|c|c|c|}
\hline & No. of Subjects (n) & Mean \pm SD & P Value \\
\hline GST Cases before Chemotherapy & 25 & $10.23 \pm 2.12$ & $\mathrm{p}<0.0001$ \\
\hline GST Cases after Chemotherapy & 25 & $12.34 \pm 1.05$ & \\
\hline \multicolumn{4}{|c|}{$\begin{array}{l}\text { Table 4. Comparison of GST Activity in Cases } \\
\text { before and after Chemotherapy }\end{array}$} \\
\hline
\end{tabular}

Table 4 Depicts: Enzyme activity of GST is increased in cases $(12.34 \pm 1.05)$ after chemotherapy as compared to cases
$(10.23 \pm 2.12)$ before Chemotherapy, and there is a significant $(p<0.0001)$ difference between cases and controls.

\section{DISCUSSION}

These findings amazed us that after cardiovascular disease malignancy is another cause of deaths in developing countries. Aetiology of malignancy is a result of genetic factors, environmental factors and behavioural factors. ${ }^{22}$ GSTs are involved in protecting cells against a wide variety of xenobiotics. Thus, it stands as biomarker of both cancer susceptibility and chemo preventive activity. ${ }^{23,24}$

Present study observes more case of males as compared to females where total cases of males were 33 while females were 17 in number and all the cases were in between age group of 25 - 75 years of age. (Table 1 ) When all cases $(8.24 \pm 1.94)$ of gastric carcinoma (stage 2 before chemotherapy and stage 3 after chemotherapy) were compared with controls (5.47 \pm $0.52)$, present study observed significant $(\mathrm{p}<0.0001)$ high difference in activity of GST, in cases when compared to controls. (Table 2). G. S. Mohammadzadeh et al. study observed similar results as present study ${ }^{25}$. Study conducted by Pasupathi $\mathrm{P}$ et $\mathrm{al}^{26}$ studied 100 patients of gastric carcinoma and observed a significant decrease in the activities of GPx, GST and GR in patients with gastric cancer. Increase in activity of GSTS may be due to overexpression of GST iso enzymes in tumour tissues. GSTs activity in plasma represents a biomarker of cellular protection. ${ }^{27}$ however there is conflicts over considering GST as marker for all tissue.

Present study observed a significant increase $(p<0.0001)$ in activity of GSTs in stage III patients with gastric carcinoma after chemotherapy. (Table 3) The level of Glutathione s transferase were increased in group receiving chemotherapy $(12.34 \pm 1.05)$ as compared to stage 1 stage 2 group not receiving chemotherapy $(10.23 \pm 2.12)$. (Table 4$)$ It may be due to improve in levels of anti-oxidant, which may lead tissue less susceptible to oxidative stress. Present study observation supports the literature of different studies, where the description states: GST s protects cells from lipid peroxidation and $\mathrm{H}_{2} \mathrm{O}_{2}$, as it is increased by cisplatin based chemotherapy drug. ${ }^{28}$ Various studies have also observed progression in cancer and increase in GST levels has been associated with poor prognosis and drug resistance. ${ }^{14-16}$

Thus, progressive increase in levels of GST with progression of gastric cancer may be associated with drug resistance as well as poor prognosis.

\section{Limitations}

The chief limitation is the small sample size and period of time required for doing the assay.

\section{CONCLUSIONS}

Measurement of GST activity in plasma can predict gastric cancer as well as response of chemotherapy in advanced stages of cancer. GST values are helpful in predicting the radiation response. Over-expression of GST in neoplasia could 
be causal, allowing replicative advantage, or casual, accompanying clonal expansion.

Financial or Other Competing Interests: None.

\section{REFERENCES}

[1] Shi WJ, Gao JB. Molecular mechanisms of chemoresistance in gastric cancer. World J Gastrointest Oncol 2016;8(9):673-81.

[2] Ferlay J, Shin HR, Bray F, et al. Estimates of worldwide burden of cancer in 2008: GLOBOCAN 2008. Int J Cancer 2010;127(12):2893-917.

[3] Rajesh P, Dikshit, Mathur G, et al. Epidemiological review of gastric cancer in India. Indian J Med Paediatr Oncol 2011;32(1):3-11.

[4] Pavithran K, Doval DC, Pandey KK. Gastric cancer in India. Gastric Cancer 2002;5(4):240-3.

[5] Rao DN, Ganesh B, Dinshaw KA, et al. A case-control study of stomach cancer in Mumbai, India. Int J Cancer 2002;99(5):727-31.

[6] Gajalakshmi CK, Shanta V. Lifestyle and risk of stomach cancer: a hospital-based case-control study. Int J Epidemiol 1996;25(6):1146-53.

[7] Rao DN, Ganesh B. Estimate of cancer incidence in India in 1991. Indian J Cancer 1998;35(1):10-8.

[8] Ambad RS, Nagtilak S, Jape MR. Diagnostic and prognostic application of glutathione-s-transferase, lactate dehydrogenase, alkaline phosphatase and carcinoembryonic antigen pre and post treatment of chemotherapy in stomach cancer patients. Int J Res Med 2016;5(1):36-43.

[9] Hazari NR, Ambad RS, Thorat AP. Serum glutathione-Stransferases activity in esophagus cancer patients receiving chemotherapy. Esophagus 2012;50(32/18):4075 .

[10] Kushi LH, Byers T, Doyle C, et al. American cancer society guidelines on nutrition and physical activity for cancer prevention: reducing the risk of cancer with healthy food choices and physical activity. CA Cancer J Clin 2006;56(5):254-81.

[11] Yamada T, Alpers DH, Kalloo AN, eds. Textbook of gastroenterology. John Wiley \& Sons 2011.

[12] Ghadyalpatil NS, Supriya C, Prachi P, et al. Gastrointestinal cancers in India: treatment perspective. South Asian J Cancer 2016;5(3):126-36.

[13] Madhusudhan C, Saluja SS, Pal S, et al. Palliative stenting for relief of dysphagia in patients with inoperable esophageal cancer: impact on quality of life. Dis Esophagus 2009;22(4):331-6.

[14] Dikshit R, Gupta PC, Ramasundarahettige C, et al. Cancer mortality in India: a nationally representative survey. Lancet 2012;379(9828):1807-16.

[15] Järvi 0, Laurén P. On the role of heterotopias of the intestinal epithelium in the pathogenesis of gastric cancer. Acta Pathol Microbiol Scand 1951;29(1):26-44.

[16] Peters WH, Koch L, Nagengast FM, et al. Biotransformation enzymes in human intestine: critical low levels in the colon? Gut 1991;32(4):408-12.

[17] Mandal S, Kekre M, Chandrakar K. Glutathione-Stransferase and GST-Л in gastric carcinoma. JMSCR 2017;5(7):25720-7.

[18] Shiratori Y, Soma. Immuno-histochemical detection of the placental from of glutathione-s-transferase in dysphasic of neoplastic human cancer cervix lesions. Cancer 1987;87(24):6806-9.

[19] Niitsu Y, Takahashi Y, Saito T, et al. Serum glutathione-Stransferase-pi as a tumour marker for gastrointestinal malignancies. Cancer 1989;63(2):317-23.

[20] Hirata S, Odajima T, Kohama G, et al. Significance of glutathione S-transferase-pi as a tumour marker in patients with oral cancer. Cancer 1992;70(10):2381-87.

[21] Hayes PC, Bouchier IA, Beckett GJ. Glutathione Stransferase in humans in health and disease. Gut 1991;32(7):813-18.

[22] Habig WH, Pabst MJ, Jakobay WB. Glutathione-Stransferases. The first enzymatic step in mercapturic acid formation. J Biol Chem 1974;249(22):7130-9.

[23] Gallo A, Cha C. Updates on esophageal and gastric cancers. World J Gastroenterol 2006;12(20):3237-42.

[24] Peickett MCB. Glutathione-s-transfere and carcinogenesis. Taytor Francis London 2007;28(2):46570.

[25] Mohammadzadeh GS, Moghadam SN, Rasaee MJ, et al. Measurement of glutathione S-transferase and its class-pi in plasma and tissue biopsies obtained after laparoscopy and endoscopy from subjects with esophagus and gastric cancer. Clin Biochem 2003;36(4):283-8.

[26] Pasupathi P, Saravanan G, Chinnaswamy P, et al. Glutathione, glutathione-dependent enzymes and antioxidant status in gastric carcinoma patients. J Appl Biomed 2009;7(2):101-9.

[27] Hayes PC, Bouchier IDH. GST in humans in health \& diseases. Gut 1991;32(3):8138-39.

[28] Tschida S, Sato K. "Glutathione-s-transfere" and cancer cirt. Rew Biochem No Bio 1992;27(4):337-84. 